\title{
Clinical skills as a vehicle for interprofessional learning
}

Interprofessional education (IPE) is defined as "occasions when two or more professions learn with, from and about each other to improve collaboration and the quality of care". ${ }^{1}$ The World Health Organization (WHO) confirmed their commitment to IPE in their Framework For Action on Interprofessional Education and Collaborative Practice in 2010 by stating that "there is sufficient evidence to indicate that effective IPE enables effective collaborative practice" and that "collaborative practice strengthens health systems and improves health outcomes". ${ }^{2}$ Whilst not being prescriptive about how this is done, the WHO clearly requests a commitment to building IPE into new and existing health-related curricula. ${ }^{2,3}$

A wide variety of IPE models are now in existence and the challenges of setting up, maintaining and evaluating a sustainable IPE initiative are well documented. ${ }^{4}$ The global community therefore needs to share their experiences and lessons learnt so that educators can elicit best practice in delivering IPE. In 2016, The Clinical Teacher published a Clinical Teachers' Toolbox titled 'Developing interprofessional education: putting theory into practice, ${ }^{5}$ which looked at IPE curriculum development, pitfalls and challenges and described the model at Griffith University, Australia. Norwich Medical School (NMS) at the University of 
East Anglia (UEA) in the United Kingdom (UK) has expanded on the steps presented by Teodorczuk and colleagues ${ }^{5}$ to further help those looking to take on the challenge of implementing IPE at their organisations. The steps presented in this toolbox specifically relate to UEA's interprofessional clinical skills sessions (ICS) that allow students to learn and practise clinical and prescribing skills in a practical environment with other allied health professionals. The most recently developed ICS, involving paramedic and medical students, is presented in more detail in an earlier issue of this journal. ${ }^{6}$ After 15 years of championing IPE at UEA, we can confidently say that the ICS are one of the most valued IPE interventions by our students. Furthermore, in the latest General Medical Council review, NMS was commended for "the innovative teaching the school is providing using other health and social care professionals and students". ${ }^{7}$

The six steps presented in Box 1 and elaborated in the text are intended to provide further insight to educators intending to develop any IPE, and offer particular support to those interested in focussing their intervention on clinical skills.

PLEASE INSERT BOX 1 HERE 
1. Design primarily for meaningful, authentic clinical skills

2. Balance the content carefully between professions

3. Start with pilots and build, using evaluation constructively

4. Reflect with students

5. Don't underestimate the administrative burden

6. Plan for sustainability

Box 1. Six steps to consider when developing sustainable IPE.

\section{Design primarily for meaningful, authentic clinical skills}

WHO have requested that "health system planners and educators must help learners transition from education to the workplace". ${ }^{2}$ One approach is by making undergraduate education as authentic as possible, wherever possible. This has also been highlighted by Nisbet et al. who found that real-life authentic experiences encouraged a team approach and collaboration through real experience. ${ }^{8}$ Indeed, IPE lends itself to authentic learning experiences and is most effective when initiatives are developed with this as a priority, as stated in the most recent Best Evidence in Medical Education (BEME) systematic review of the effects of IPE. ${ }^{4}$ However, according to Reeves and colleagues, undergraduate students don't always feel that their IPE sufficiently relates to what they perceive 
to be their future clinical practice. ${ }^{4}$ This echoes the views of some students at NMS, which inspired the development of ICS.

The original ICS at NMS featured medical and pharmacy students and was designed to improve medical students' knowledge and confidence in prescribing skills. Uni-professional prescribing sessions at the time were being delivered in the form of undergraduate seminars and workshops. A group of NMS graduates in their first two years of working were interviewed by one of the authors (LB) for her masters dissertation., The graduates explained that they learnt practical prescribing from pharmacists on the wards. The clinical skills team therefore decided to recreate the learning reportedly happening in the workplace by offering an opportunity for medical and pharmacy students to learn from one another in a pre-registration yet clinical setting. The aim of ICS is to present common prescribing and pharmacy (ie.formulation availability) issues encountered on wards, or in the community, and allow students to learn by working through these tasks together. The tasks are scenario-based and designed to be as authentic as possible, involving simulated patients (actors), real drug charts and medications, and time-sensitive situations. Box 2 shows an example scenario.

INSERT BOX 2 HERE 


\section{INSTRUCTION TO STUDENTS}

The medical student will take the lead in assessing the patient in this station.

The pharmacy student will provide the medical student with information relating to the medications the patient is taking, further medications to be prescribed, taking into consideration any hospital guidelines provided.

This station contains a simulation model called SIMMAN®. Please treat the model as if it was a real patient.

You are working in the Emergency department and you are called to see a 57-year old, male, Darren Jones, who has been brought in by his friend. He was having a drink in the pub and started to vomit blood. A few minutes later he passed some black diarrhoea in the toilet of the pub and then collapsed. He has brought his tablets with him. Work together to establish a possible cause for his presentation. Your task is to:

- Make an appropriate examination

- Institute initial monitoring and therapy

- Make a preliminary diagnosis and provide the appropriate drug therapy

You have a total of 20 minutes for this station, which includes feedback time.

\section{SIMMAN INSTRUCTIONS}

Pulse: 120 beats per minute (rising over time)

Airways: normal

Lungs: normal

Respiratory rate: 19

Monitor controls (once applied): Standard pressure $\mathrm{O}_{2} 99 \%$ (on air); Atrial Fibrillation

Blood pressure: $85 / 45$

Vocal sounds: vomiting

\section{REQUIRED EQUIPMENT}

Oxygen supply and green tubing

Variety of oxygen masks (24/28/40 and $60 \%$ plus reservoir mask)

IV cannulas

IV fluids

IV emergency drugs

British National Formulary (the pharmaceutical reference guide for prescribing healthcare professionals in the UK).

\section{LIST OF DRUGS}

Warfarin: $2 \mathrm{mg} / 3 \mathrm{mg}$, alternate days

Digoxin: $125 \mathrm{mcg}$, once daily

Bendroflumethiazide: $2.5 \mathrm{mg}$, once daily

Yellow Book - specifies warfarin for Arial Fibrillation Target International Normalised Ratio 2.5

Box 2. Example of a scenario led by a medical student: Assessment and management: simulated patient 
The focus of ICS is to recreate original workplace examples of interprofessional collaboration and learning, it is problem-based and highly interactive. This teaching model has subsequently been applied to interprofessional learning opportunities involving nursing and paramedic 6 students - customising the scenarios to be contextually important to the professions involved.

\section{Balance the content carefully between professions}

The WHO promotes the use of IPE to produce "collaborative practice-ready health professionals, poised to take on complex or emergent problems and solve them together". ${ }^{2}$ This involves all individuals being able to act as both team leader and team member, while understanding not only one's own role and expertise, but those of others.

Each ICS at NMS currently features medical students working collaboratively with students from another profession. The sessions are designed to engage both professions equally, with some stations being led by medical students and others by their colleague (e.g. Box 2). For successful IPE to occur, each scenario must have a role for both students and utilise both profession's expertise, even if one is more dominant. This not only helps students develop the necessary skills to be an 
effective leader and follower, but also clarifies roles while demonstrating how professions can optimise care through efficient collaboration.

This approach is supported by Bradley et al. who suggested that "shared outcomes promote IPE as a concept and as a practical implementation", they encourage IPE that is "contextually important to both groups". ${ }^{9}$ In order to achieve this at NMS, staff and student feedback were collected following each pilot to help adjust scenario content and ensure a fair and useful balance.

3. Start with pilots and build, using evaluation constructively

The WHO describes willingness to update, renew and revise existing curricula as one of the main mechanisms that shapes effective IPE ${ }^{2}$. The ICS at NMS was developed gradually and dynamically using feedback from students and staff as they were exposed to it. To date, more than 600 students participate in ICS annually from medicine, nursing, pharmacy and paramedic sciences. (Figure 1). 
PLEASE INSERT FIGURE 1 HERE

\begin{tabular}{|c|c|c|c|c|c|c|c|}
\hline 2002- 2010 & 2010-2011 & 2011-2012 & 2012-2013 & 2013-2014 & 2014-2015 & 2015-2016 & 2016-2017 \\
\hline \multirow[t]{3}{*}{$\begin{array}{l}\text { Class-room } \\
\text { based IPE }\end{array}$} & $\begin{array}{l}\text { Class-room } \\
\text { based IPE }\end{array}$ & $\begin{array}{l}\text { Class-room } \\
\text { based IPE }\end{array}$ & $\begin{array}{l}\text { Class-room } \\
\text { based IPE }\end{array}$ & $\begin{array}{l}\text { Class-room } \\
\text { based IPE }\end{array}$ & $\begin{array}{l}\text { Class-room } \\
\text { based IPE }\end{array}$ & $\begin{array}{l}\text { Class-room } \\
\text { based IPE }\end{array}$ & $\begin{array}{l}\text { Class-room } \\
\text { based IPE }\end{array}$ \\
\hline & $\begin{array}{l}\text { Pilot ICS } \\
\text { pharmacy }\end{array}$ & $\begin{array}{l}\text { ICS } \\
\text { pharmacy }\end{array}$ & $\begin{array}{l}\text { ICS } \\
\text { pharmacy }\end{array}$ & $\begin{array}{l}\text { ICS } \\
\text { pharmacy }\end{array}$ & $\begin{array}{l}\text { ICS } \\
\text { pharmacy }\end{array}$ & $\begin{array}{l}\text { ICS } \\
\text { pharmacy }\end{array}$ & $\begin{array}{l}\text { ICS } \\
\text { pharmacy }\end{array}$ \\
\hline & & $\begin{array}{l}\text { Pilot ICS } \\
\text { nursing }\end{array}$ & $\begin{array}{l}\text { Pilot ICS } \\
\text { nursing }\end{array}$ & $\begin{array}{l}\text { ICS } \\
\text { nursing }\end{array}$ & $\begin{array}{l}\text { ICS } \\
\text { nursing }\end{array}$ & $\begin{array}{l}\text { ICS } \\
\text { nursing }\end{array}$ & $\begin{array}{l}\text { ICS } \\
\text { nursing }\end{array}$ \\
\hline \multicolumn{6}{|c|}{$\begin{array}{l}\text { Paramedic ICS } \\
\text { Pharmacy ICS } \\
\text { Nursing ICS }\end{array}$} & $\begin{array}{l}\text { Pilot ICS } \\
\text { paramedics }\end{array}$ & $\begin{array}{l}\text { ICS } \\
\text { paramedics }\end{array}$ \\
\hline
\end{tabular}

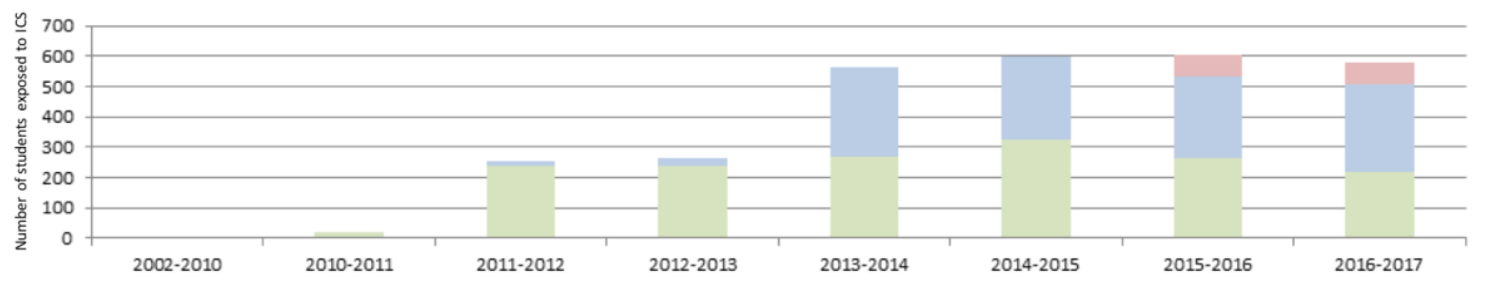

Year

Figure 1. The figure shows the timescale over which the ICS programme at NMS was built, the progressive student exposure to IPE and the increasing numbers of students and professions accommodated

The original ICS pilot consisted of 11 scenarios. Students were asked which scenarios they found beneficial and which helped them accomplish their learning objectives. Similarly, tutors expressed opinions about which scenarios encouraged students to work together and which left a profession idle. This feedback selected six scenarios to roll out to the full cohort.

Each time a new profession joined, another pilot was run. The pilots produced immediate, manageable feedback used to decide which scenarios should be kept, replaced or adjusted. They were hugely valuable to identify problems, and to evaluate efficacy prior to larger resource investment. Paquette-Warren et al. describe a similar process where they also modified their IPE course during implementation to better meet the needs of learners. ${ }^{10}$ 


\section{Reflect with students}

Guided reflection following an IPE experience has been confirmed by several studies as beneficial to reported student satisfaction, efficacy and achieving learning outcomes..$^{411,12}$

Most ICS scenarios now dedicate as much time to debriefing and discussion as the practical tasks. In many cases, one tutor can oversee three pairs completing the same scenario concurrently, and then debrief with all six students. This is economical in terms of staff requirements, but also creates better discussion as each pair has slightly different ideas and experiences. Tutors are trained in how to give constructive feedback on students' clinical and interprofessional skills, and are asked to share their own profession's expert knowledge of the clinical skill(s) applied in their scenario ${ }^{6}$ rather than remaining professionally neutral, (which differs from our IPL facilitators). ${ }^{13}$ 
In order to support student reflection around collaboration, tutors ask questions about how they worked together, how they would approach the situation in the future and what they learnt, both about the skill and about their colleagues. This immediate debrief and guided reflection is highly praised by students in the compulsory NMS end of year evaluation as something they find particularly helpful.

\section{Don't underestimate the administrative burden}

Administrative difficulties are widely reported as a major challenge to the implementation and long-term viability of IPE ${ }^{4,12}$. In 65 studies reviewed by AbuRish et al., $78.3 \%$ of reported 'IPE barriers' were due to logistical problems linked to time-tabling, matching students, staff time and inadequate administrative support. ${ }^{14}$ The difficulty of aligning the time-tables of different professions, each with their own semesters, examination dates and clinical commitments is not to be underestimated. This challenge increases with larger cohort sizes or geographical variables. Additionally, station/scenario design, set up and student allocation is complex and resource intensive. 
At UEA, there is a team in the 'Centre for Interprofessional Practice' (CIPP) that has been responsible for the delivery of IPE since 2003. CIPP has developed and delivered IPE in different formats to all healthcare students at UEA, and so is experienced in coordinating learning events across schools (e.g. medicine, health sciences and pharmacy) and faculties (e.g. Faculty of Medicine and Health Sciences, and Faculty of Science). From 2017, IPE has transitioned to being delivered by the schools themselves with CIPP instead overseeing the process to ensure high quality IPE. The complexity of coordinating these sessions is clearly documented in numerous IPE studies ${ }^{4,15}$ and warrants due consideration - a recommendation that has been emphasised during this transition period.

\section{Plan for sustainability}

Many IPE initiatives report problems with sustainability and ongoing support after initial implementation. ${ }^{4}$ This may explain why the majority of interventions reviewed by Abu-Rish et al. were single event activities. ${ }^{15}$ ICS are resource intensive - they require skilled tutors, clinical space, equipment and simulated patients. When designing an intervention, it is therefore important to quantify the funding, resource and time requirements, and plan how these will be met in the future. 
The existence of CIPP at NMS has meant that we have avoided many of the struggles experienced by other institutions regarding staffing, funding and organisation. The cost of ICS at our institution is estimated to be $£ 37$ (US\$53) per student, per session. CIPP receives annual funding from the local National Health Service (NHS) Education and Training board (who are responsible for providing education and training for our healthcare workforce). A proportion of this funding was used to cover the costs of ICS. From 2017, CIPP was asked by the Faculty of Medicine and Health Sciences at UEA to focus on interprofessional collaboration in practice, to facilitate the transition of IPE into the practice setting. As a result, the schools became responsible for sourcing ICS funding from their combined budgets and had to plan for sustainability. The long-term effect of transitioning IPE delivery into schools at UEA remains to be seen. However, as ICS is now wellestablished, schools are able to plan for costs and resource requirements and staff are confident they will continue to provide these invaluable learning opportunities.

Conclusion 
The WHO has made a call for all educators to embed IPE and collaborative practice into the services they deliver ${ }^{(3)}$. The BEME systematic reviews are evaluating IPE initiatives regularly to provide evidence-based guidance for the development of sustainable and effective IPE across pre and post-registration institutions (2). We have used our experience of developing a successful ICS programme at a UK based medical school to supplement the useful guidance provided in a previous Clinical Teacher's Toolbox ${ }^{(5)}$ in the hope that this may assist others who are considering championing IPE at their institution. Over the seven years that our programme has run we found authenticity, balanced interaction and reflection to be essential components of effective IPE. We believe that dynamic development using continuous evaluation, planning for sustainability and early recruitment of administrative support are integral for building and maintaining a successful initiative. These principles are repeated in a wide range of IPE literature and are our strongest recommendations for those looking to support our future healthcare professionals by investing in IPE.

Word count 1972 (not including words in textboxes/figure)

References:

1) Centre for the Advancement of Interprofessional Education (CAIPE). Defining IPE. CAIPE, 2002. Available at: http://caipe.org.uk/about-us/defining-ipe//. Accessed February 2018. 
2) World Health Organisation (WHO). Health Professions Networks Nursing and Midwifery, Human Resources for Health. Framework For Action on Interprofessional Education and Collaborative Practice. Geneva: WHO, 2010. Available at: http://www.who.int/hrh/resources/framework action/en/. Accessed February 2018.

3) WHO. Global strategy on human resources for health: Workforce 2030. WHO, 2014(pp 11,13,16). Available at: http://www.who.int/hrh/resources/global strategy2030enprintversion.pdf?ua=1 Accessed February 2018.

4) Reeves S, Fletcher S, Barr H, Birch I, Boet S, Davies N, McFadyen A., Rivera J, Kitto S. A Best Evidence in Medical Education (BEME) systematic review of the effects of interprofessional education: BEME Guide No. 39. Medical Teacher 2016; 38(7): 656-668.

5) Teodorczuk A, Kheng Khoo T, Morrissey S, Rogers S. Interprofessional Education: Putting theory into Practice. Clin. Teach. 2016;13:7-12.

6) Nagraj S, Harrison J, Hill L, Bowker L,Lindqvist S. Promoting collaboration in emergency medicine. Clin Teach 2018;15:1-6.

7) GMC (General Medical Council). East of England Regional Review. Review of Norwich Medical School at the University of East Anglia, 2015 (pp19).

Available at: https://www.gmcuk.org/Final East of England Regional Report 2016 updated 19042016.p df 65996735.pdf Accessed February 2018

8) Nisbet G, Hendry GD, Rolls G, Field MJ. Interprofessional learning for prequalification health care students: an outcomes-based evaluation. J Interprof Care 2008; 22:57-68.

9) Bradley P, Cooper S, Duncan F. A mixed-methods study of interprofessional learning of resuscitation skills. Med Ed 2009; 43:912-922.

10)Paquette-Warren J, Roberts $S$, Foumie $M$, Tyler $M$, Brown J, Harris $S$. Improving chronic care through continuing education of interprofessional primary healthcare teams: a process evaluation. J Interprof. Care 2014; 22:399-416

11)Duffy, A. Guided reflection: a discussion of the essential components. $\mathrm{Br} \mathrm{J}$ of Nursing 2008;17:334-339.

12) LeFlore JL, Anderson M. Alternative educational models for interdisciplinary student teams. Simul Healthcare 2009; 4:135-142.

13)Freeman S., Wright A, Lindqvist $S$. (). Facilitator training for educators involved in interprofessional learning. J of Interprof Care 2010;4(4): 375-385.

14) Abu-Rish E, Kim S, Choe L, Varpio L, Malik E, White A. A. ... Zierler B. Current trends in interprofessional education of health sciences students: A literature review. $J$ of Interprof Care 2012; 26:444-451.

15)Hammick M, Freeth D, Koppel I, Reeves S, Barr H. A best evidence systematic review of interprofessional education: BEME guide no.9. Med Teach 2007; 29: 735-751. 